\title{
Southern Sami Language
}

National Cancer Institute

\section{Source}

National Cancer Institute. Southern Sami Language. NCI Thesaurus. Code C154118.

A Uralic Sami language spoken mostly in Snasa, Royrvik, Roros, and Hattfjelldal in Norway. 